Relations industrielles

Industrial Relations

\title{
Les Business School Américaines, par Michel Chevalier et Jean François de Chorivit, Paris, Entreprise Moderne d'Édition, 1970, 122 pp.
}

\section{Jean-Pierre Beaulieu}

Volume 26, numéro 1, 1971

URI : https://id.erudit.org/iderudit/028209ar

DOI : https://doi.org/10.7202/028209ar

Aller au sommaire du numéro

Éditeur(s)

Département des relations industrielles de l'Université Laval

ISSN

0034-379X (imprimé)

1703-8138 (numérique)

Découvrir la revue

Citer ce compte rendu

Beaulieu, J.-P. (1971). Compte rendu de [Les Business School Américaines, par Michel Chevalier et Jean François de Chorivit, Paris, Entreprise Moderne d'Édition, 1970, 122 pp.] Relations industrielles / Industrial Relations, 26(1), 255-255. https://doi.org/10.7202/028209ar

Tous droits réservés @ Département des relations industrielles de l'Université Laval, 1971
Ce document est protégé par la loi sur le droit d'auteur. L'utilisation des services d'Érudit (y compris la reproduction) est assujettie à sa politique d'utilisation que vous pouvez consulter en ligne.

https://apropos.erudit.org/fr/usagers/politique-dutilisation/ 
it ; the reason for the disadvantaged economic position of black workers and the main lines of remedial action; the problem of structural unemployment and its reduction through retraining and relocation programs; the problem of restraining wage and price increases during periods of high employment; the dimensions of poverty and new antipoverty proposals such as the negative income tax. These and other issues of labor market policy are discussed more fully than in previous editions".

Ces sujets méritent d'être signalés et constituent, à notre avis, l'intérêt de cette nouvelle édition d'un volume déjà considéré comme un classique, ce qui revient presque à dire qui a fait sa marque demeure source de référence mais n'est plus à la fine pointe des discussions d'aujourd'hui. Par l'étude de tels sujets Reynolds anime l'économique du travail, la situe sur un autre plan que le plan abstrait de la pure analyse théorique, il la place dans le contexte social d'aujourd'hui et commente la marge qu'il y a entre le modèle et le réel.

C'est une optique semblable qui marquait le volume de Woods et Ostry dans certains chapitres. Nous sommes heureux de constater que peu à peu des économistes, auteurs, tentent de combler le fossé entre la théorie et le réel. Galbraith aurait-il été compris?

\section{Jean-Pierre BEAULIEU}

Psychologie du groupe, par M.A. Robert, manuel théorique et pratique de l'animateur. Bruxelles, Coll. «Humanisme d'aujourd'hui », Editions Vie Ouvrière, 1969, 173 pp.

Voici un petit ouvrage extrêmement bien fait dans sa conception, sa présentation et sa formulation. Il comporte une partie théorique sur les groupes ainsi qu'une partie consacrée aux techniques de groupe. L'auteur est un véritable pédagogue; il sait amener le lecteur à comprendre des notions difficiles qu'il explique avec une clarté et une précision sans verser dans des simplifications superficielles. Avec l'importance que prend aujourd'hui le travail en groupe, cet ouvrage est destiné à rendre des services inappréciables à tous ceux qui étudient les phénomènes de groupe et leur réalité concrète.

Gérard DION
Les Business Schools Américaines, par Michel Chevalier et Jean François de Chorivit, Paris, Entreprise moderne d'édition, 1970, 122 pp.

Petit volume intéressant sur les écoles américaines d'administration écrit par les auteurs à partir de leur expérience comme étudiants à Harvard. C'est un peu une autre découverte de l'Amérique à un niveau micro-économique ; découverte qui entraîne la comparaison avec le système français dont on démontre les grandes faiblesses et l'anachronisme face aux besoins de la société actuelle. Le système américain d'éducation, surtout au niveau gradué, est très bien développé. Les ressources financières et humaines ne manquent pas au point où les institutions de haut-savoir se permettent une saine concurrence dans la qualité de leur enseignement, dans la compétence de leurs diplômés. Si cette situation a fait réfléchir les auteurs français, elle pourrait peut-être porter à la réflexion certaines personnes du milieu universitaire québécois et c'est pourquoi nous leur recommandons cette lecture.

\section{Jean-Pierre BEAULIEU}

L'entretien d'appréciation : six dialogues entre chef et subordonné, par N.R. Maier, Paris, Entreprise Moderne d'Edition, 1968, 290 pp.

L'ouvrage de Norman Maier est déjà connu aux Etats-Unis et au Canada puisqu'il a été publié en langue anglaise en 1958. Comme il a connu une très grande diffusion, l'Entreprise moderne d'édition en a fait une excellente traduction.

On sait que l'entretien d'appréciation cause énormément d'embarras à tout cadre dirigeant qui doit à des moments précis rencontrer ses subordonnés pour leur communiquer ce qu'il pense d'eux et surtout de leur comportement au travail. Même s'ils appréhendent cette confrontation, la plupart des gens dans une situation de subalternes désirent être appréciés à leur 《juste valeur» et connaître ce que leur supérieur pense d'eux. C'est là une responsabilité auquelle peut difficilement se soustraire quelqu'un qui coordonne et supervise le travail d'autres personnes. 